\title{
Manufacturing Regenerated Woody Dyed Fiber from Waste MDF Using Natural Dyes ${ }^{1}$
}

\author{
Seon-Gyeong $\mathrm{JU}^{2} \cdot$ JeongKwan $\mathrm{ROH}$ (D) $^{2, \dagger}$
}

\begin{abstract}
To assign the functionality of the regenerated fiber from waste MDF(wMDF) made of pitch pine, we examined the dyeing characteristics of natural dyes, sappan wood as a polychromatic natural red series, monochromatic gardenia as a yellow series, and indigo blue series. For nonemordanting dye, the colors of regenerated fiber dyed by sappan wood and gardenia were reddish yellow (YR) and yellow (Y) series, respectively, and dyeing conditions were appropriate a $30 \sim 50 \mathrm{~g} / \mathrm{L}$ of dyeing materials at $60{ }^{\circ} \mathrm{C}$ for 60 minutes of dyeing time. We obtained regenerated woody dyed fibers (Re-WDF), YR to the red (R) series by premordanting with $\mathrm{Al}$ and $\mathrm{Cu}$ mordant for sappan wood and the purplish red (RP) series by Fe premordanting. In the case of gardenia, only Y series colors were developed in nonemordanting dye or all three mordants. Indigo dye produced Re-WDF with greenish yellow (GY) tone at $1 \%$, green $(\mathrm{G})$ tone at $3 \%$, and blue (B) tone at $5 \%$ concentration or more. Re-WDF with indigo showed the best light fastness followed by sappan wood and gardenia. In particular, the light fastness of Re-WDF with gardenia was very poor. The light fastness was somewhat improved by premordanting $(\mathrm{Fe}>\mathrm{Cu}>\mathrm{Al})$ both sappan wood and gardenia dyes.
\end{abstract}

Keywords: natural dyes, waste MDF, regenerated woody dyed-fiber, color difference, K/S, light fastness

\section{INTRODUCTION}

Recently, a slogan recalling low carbon green growth is frequently encountered in relation to global warming. This is caused by a wide variety of complex causes, but the most influential factor is the increased concentration of carbon dioxide produced by the burning of fossil fuels. Therefore, in order to reduce the concentration of carbon dioxide in the combustion process by even a little, the service life of materials containing carbon needs to be extended. It is also environmentally useful to prolong the life of wood and wood-based materials as they are the world's most carbon-rich renewable resources.

This research group examined the possibility of dyeing regenerated fibers by reactive, direct, and bat dyes to recycle waste medium density fiberboard (wMDF) as it is currently not recycled at all in spite of it being the most produced wood material in Korea. As a result, it was confirmed that dyeing is relatively easy with certain dyes that are mainly used for dyeing cellulosic materials, and that there is no significant difference in dyeing characteristics between virgin fibers and regenerated fibers (Ju et al., 2017). In addition, optimal dyeing conditions (dye concentration, amount of salt and alkali added, dyeing temperature, and time)

${ }^{1}$ Date Received January 14, 2020, Date Accepted January 29, 2020

2 Department of Interior Materials Engineering, Gyeongnam National University of Science Technology, Jinju 52725, Republic of Korea

† Corresponding author: JeongKwan ROH (e-mail: arohjk@gntech.ac.kr, ORCID: 0000-0002-3146-951X) 
were obtained when dyed regenerated fibers from wMDF were stained with Reactive Red H-E3B (Bismonochlorotriazine (MCT) / MCT type) and Reactive Red RB 133\% (Bis-MCT / Vinyl sulphone type)(Ju et al., 2019). However, in order to utilize the wMDF obtained around our lives as a functional molding materials, Re-WDF needs to be manufactured using natural dyes that can be obtained around our lives.

Dyeing with natural dyes is mainly applied to fabrics. Natural dyeing for cellulosic fibers was performed mainly on Hanji. The dye materials used for natural dyeing of Hanji include gardenia, saffron, safflower, cork-tree, pagoda tree, onion-peelings, mugwort, clove tree (Jeon et al., 2000; 2003; 2006), Neolitsea sericea Koidz extract (Jo et al., 2007), sappan wood, gardenia, gallnut (Park et al., 2009; 2010; 2011), flowers of pagoda tree, gardenia (Yoo et al., 2009; 2011), gallnut, leaves of amur maple, nutshell of chestnut, persimmon juice (Lee et al., 2009), Alnus japonica fruit extract (Choi et al., 2009). However, studies of dyeing regenerated woody fibers with natural dyes have not been conducted until now.

Therefore, we obtained regenerated wood fiber from the waste furniture which can be easily accessed around our daily lives, and examined the feasibility of producing dyed regenerated fiber given various color functions by natural dyes. The natural dyes used in this study were examined for the dyeing properties of representative red-based sappan wood, yellow-based gardenia and blue-based commercial indigo.

\section{MATERIALS and METHODS}

\subsection{Materials}

\subsubsection{Regenerated wood fiber from WMDF}

Regenerated fiber was used by dissociating MDF with a specific gravity of 0.62 manufactured from pitch pine (Pinus rigida $\mathrm{M}$.) and urea resin. The regenerated fiber was prepared by $250 \mathrm{ml}$ of distilled water added to $50 \times 50 \times 12 \mathrm{~mm}$ MDF and immersed at $25{ }^{\circ} \mathrm{C}$ for 48 hours. After defibrated with a home-use mixer for 5 minutes, the resultant was filtered through a $300 \mu \mathrm{m}$ screen and dried.

\subsubsection{Extraction of natural dye and mordants}

Chinese sappan wood(Caesalpinia sappan L) and gardenia(Gardenia jasminoides E.) were purchased as dyeing materials, and the moisture content was $9.5 \%$ and $8.0 \%$, respectively. The extractions of sappan wood and gardenia were carried out using distilled water to set the amount of raw materials to $10,20,30,50,100$ $\mathrm{g} / \mathrm{L}$, heated to $90{ }^{\circ} \mathrm{C}$ for 50 minutes, and then maintained for 30 minutes at $90{ }^{\circ} \mathrm{C}$. Indigo (India) powder was used as is on the market. Aluminum ammonium sulfate dodecahydrate, Copper (II) acetate anhydrous, Iron (II) sulfate heptahydrate (Extra pure, Daejung) as mordants, sodium hydrosulfite and sodium carbonate andydrous (Extra pure, Daejung) as a reducing agent of indigo dye and $0.1 \mathrm{M}$ sodium hydroxide solution as a $\mathrm{pH}$ control agent were used.

\subsection{Methods}

\subsubsection{Dyeing}

The dyeing was performed in a tall beaker with regenerated fiber and the definite amount of raw materials extracts $(10,20,30,50,100 \mathrm{~g} / \mathrm{L})$ at a liquid ratio of 1:50 and for 60 minutes at $60{ }^{\circ} \mathrm{C}$. The effects of dyeing temperature and time of sappan wood and gardenia at $50 \mathrm{~g} / \mathrm{L}$ of raw materials were examined by varying the temperature of $50,60,70$ and $80{ }^{\circ} \mathrm{C}$ at 60 minutes and dyeing time of 30,60, 90, 120 and 150 minutes at $60{ }^{\circ} \mathrm{C}$. The premordanting of sappan wood and gardenia were conducted for 40 minutes at $40{ }^{\circ} \mathrm{C}, 5 \%$ (O.W.F) addition of the mordant, in a liquid ratio of $50: 1$, and then filted and washed. Subsequent dyeing was carried out with $50 \mathrm{~g} / \mathrm{L}$ of sappan wood and 
gardenia extracts for 60 minutes at a liquid ratio of 1:50 and $60{ }^{\circ} \mathrm{C}$. Indigo, a commercial natural dye, was dyed under the same conditions at indigo concentration of 1,3 and $5 \%$ (O.W.F).

\subsubsection{Preparation of dyed fiber sheet}

Sheets for measuring the dyeing property, color and light fastness were manufactured by adding the same amount of distilled water to the regenerated fiber dyes in different conditions and blended with a mini-mixer for 2 minutes, and then filtered through the Whatman filtering paper, and compressed for 5 minutes at $50{ }^{\circ} \mathrm{C}$.

\subsubsection{Color measurement}

The surface color of the Re-WDF was measured using Minolta CM-3800d (Japan). The color difference according to the dyeing was calculated by the difference between the sheets prepared by the same method put the water and the dye solution to the regenerated fiber. The K/S value was calculated by Kubelka-Munk equation after measuring the surface reflectance of each dyed sample.

\subsubsection{Color fastness to light}

Light fastnesses of Re-WDF were evaluated using an accelerated weathering tester (QUV / SP, USA). UVB-313 was used as a lamp and evaluated for color difference in CIE Lab color space before and after UV irradiation treatment at a constant illumination intensity of $0.67 \mathrm{~W} / \mathrm{m}^{2}$ and temperature of $50{ }^{\circ} \mathrm{C}$.

\section{RESULTS and DISCUSSION}

\subsection{Dyeing characteristics of Re-WDF with sappan wood and gardenia}

\subsubsection{Dyeability and light fastness by amount of dye materials}

Dyeing characteristics of regenerated fibers from wMDF with red-based sappan wood which are generally known as polychromatic natural dyes and yellow-based gardenia monochromatic natural dyes were studied. The sappan wood contains dozens of pigments, but brazilin, a dihydropyran type dye and has many benzene cyclic structures, is known as a major coloring material (Lee et al., 2002). The gardenia is a carotenoide type dye and is known to be yellow by water-soluble crocin which is mainly crocetindigentiobioside (Tak et al., 2010). In order to prepare the Re-WDF from wMDF using sappan wood and gardenia, the dyeing characteristics of regenerated fiber were examined by different amounts of dyeing materials. First, the dyeing solution was obtained by extracting $10,20,30,50,100 \mathrm{~g} / \mathrm{L}$ of sappan wood and gardenia for 50 minutes at $90{ }^{\circ} \mathrm{C}$.

The dyeing yield $(\mathrm{K} / \mathrm{S})$ of Re-WDF with each dyeing solution at liquid ratio $50: 1,60{ }^{\circ} \mathrm{C}$ for 60 minutes is shown in Fig. 1. The dyeing yield of the two dyes at the wavelength of $450 \mathrm{~nm}$ increased as the amount of dye materials increased, and gardenia's dyeing yield was very high compared to sappan wood's. It was found that the maximum absorbance of the gardenia dyed fiber on the UV-VIS spectrum was shown at 450nm. This is very similar to the results reported by Watanabe et al. (1998) that the $441 \mathrm{~nm}$ absorption peak corresponds to crocin and crocetin.

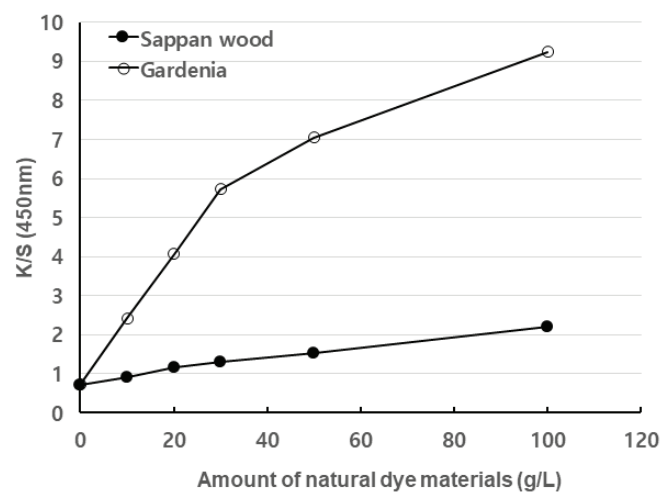

Fig. 1. Color yield of the Re-WDF by amount of natural dye materials. 
The color and color difference of Re-WDF dyed by different amounts of sappan wood and gardenia and its color of before and after a UV treatment for 24 hours are shown in Table 1.

The hue of regenerated woody fiber(control) is a yellow tone of $0.2 \mathrm{Y}$. The color of Re-WDF dyed with sappan wood displayed $9.0 \sim 9.9 \mathrm{YR}$. There is almost no change despite of the fact that the amount of dye materials increased from $10 \mathrm{~g} / \mathrm{L}$ to $100 \mathrm{~g} / \mathrm{L}$. The increased $\mathrm{a}^{*}$ and $\mathrm{b}^{*}$ indicates that red and yellow becomes stronger. As the amount of dye materials increased, the color difference of Re-WDF dyed with sappan wood also increased. The color difference at dye materials of $10 \mathrm{~g} / \mathrm{L}$ was 3.33 which corresponds to "appreciable" by the National Bureau of Standards (NBS). The color differences at 20,30, and $50 \mathrm{~g} / \mathrm{L}$ were $6.99,8.76$, and 11.10 , respectively, and that corresponds to "Much appreciable" (color difference 6.0-12.0) meaning they were colored with extremely marked changes. In addition, as the amount of sappan wood increased from 10 to $100 \mathrm{~g} / \mathrm{L}$, the values decreased slightly from 7.4 to 6.7 , while chromas increased from 4.0 to 5.9 .

For gardenia, its hue showed no change from 0.9 to $0.6 \mathrm{Y}$ even with the increased the amount of dye materials from $10 \mathrm{~g} / \mathrm{L}$ to $50 \mathrm{~g} / \mathrm{L}$, and $9.5 \mathrm{YR}$ at 100 $\mathrm{g} / \mathrm{L}$. As the amount of gardenia increased, both $\mathrm{a}^{*}$ and $\mathrm{b}^{*}$ increased indicating that red and yellow became stronger. In particular, the color difference of Re-WDF stained with gardenia of $10 \mathrm{~g} / \mathrm{L}$ was 21.71 as it corresponds to another color of NBS's "very much" $(12.0+)$. Gardenia's coloring power was excellent and its color difference became larger as the amount of dye materials increased.

Fig. 2 shows the light fastness of Re-WDF regarding the amount of sappan wood and gardenia as they were evaluated by the color difference in CIE Lab color space before and after a $24 \mathrm{hr}$ UV irradiation with an illumination of $0.67-\mathrm{W} / \mathrm{m}^{2}$ at a temperature of $50{ }^{\circ} \mathrm{C}$ using accelerated weathering tester.

The color difference of the un-dyed regenerated wood fiber from wMDF showed a great color difference by irradiation of ultraviolet and it was confirmed that the

Table 1. Color changes of the Re-WDF dyed with various amount of natural dyes

\begin{tabular}{|c|c|c|c|c|c|c|c|c|c|c|c|}
\hline \multirow{3}{*}{$\begin{array}{c}\text { Type of } \\
\text { natural dye }\end{array}$} & \multirow{3}{*}{$\begin{array}{c}\text { Amount of } \\
\text { natural dye } \\
(\mathrm{g} / \mathrm{L})\end{array}$} & \multicolumn{4}{|c|}{ Hunter's Value } & \multicolumn{6}{|c|}{ Munsell's Value } \\
\hline & & \multirow{2}{*}{$\mathrm{L}^{*}$} & \multirow{2}{*}{$a^{*}$} & \multirow{2}{*}{$b^{*}$} & \multirow{2}{*}{$\Delta \mathrm{E}^{*}$} & \multicolumn{2}{|c|}{$\mathrm{H}$} & \multicolumn{2}{|c|}{$\mathrm{V}$} & \multicolumn{2}{|c|}{$\mathrm{C}$} \\
\hline & & & & & & Before & After ${ }^{2)}$ & Before & After ${ }^{2}$ & Before & After $^{2}$ \\
\hline Control & 0 & 76.05 & 5.21 & 22.18 & _- & $0.2 \mathrm{Y}$ & $0.6 \mathrm{Y}$ & 7.5 & 6.7 & 3.5 & 5.3 \\
\hline \multirow{5}{*}{$\begin{array}{c}\text { Sappan } \\
\text { wood }\end{array}$} & 10 & 74.51 & 6.72 & 24.71 & 3.33 & 9.9YR & $0.1 \mathrm{Y}$ & 7.4 & 6.6 & 4.0 & 5.3 \\
\hline & 20 & 72.91 & 8.23 & 27.64 & 6.99 & $9.8 \mathrm{YR}$ & $9.6 \mathrm{YR}$ & 7.2 & 6.5 & 4.5 & 5.4 \\
\hline & 30 & 72.12 & 9.04 & 29.00 & 8.76 & $9.6 \mathrm{YR}$ & $9.4 \mathrm{YR}$ & 7.2 & 6.4 & 4.8 & 5.6 \\
\hline & 50 & 70.69 & 10.31 & 30.44 & 11.10 & $9.4 \mathrm{YR}$ & $9.0 \mathrm{YR}$ & 7.0 & 6.3 & 5.1 & 5.6 \\
\hline & 100 & 67.52 & 12.81 & 34.26 & 16.68 & $9.0 \mathrm{YR}$ & $8.1 \mathrm{YR}$ & 6.7 & 5.9 & 5.9 & 5.9 \\
\hline \multirow{5}{*}{ Gardenia } & 10 & 72.05 & 9.60 & 43.06 & 21.71 & $1.8 \mathrm{Y}$ & $0.9 \mathrm{Y}$ & 7.2 & 6.6 & 6.8 & 5.7 \\
\hline & 20 & 69.51 & 12.52 & 51.50 & 30.93 & $1.5 \mathrm{Y}$ & $0.9 \mathrm{Y}$ & 6.9 & 6.6 & 8.2 & 5.9 \\
\hline & 30 & 67.83 & 14.88 & 56.88 & 36.95 & $1.1 \mathrm{Y}$ & $0.7 \mathrm{Y}$ & 6.8 & 6.5 & 9.1 & 6.3 \\
\hline & 50 & 66.32 & 17.52 & 59.51 & 40.50 & $0.4 \mathrm{Y}$ & $0.6 \mathrm{Y}$ & 6.6 & 6.5 & 9.7 & 6.4 \\
\hline & 100 & 64.82 & 20.84 & 63.38 & 45.48 & $9.5 \mathrm{YR}$ & $0.2 \mathrm{Y}$ & 6.5 & 6.4 & 10.6 & 7.0 \\
\hline
\end{tabular}

1) Dyeing conditions ; Temperature : $60{ }^{\circ} \mathrm{C}$, Time : 60 minutes

2) After of ultraviolet irradiation treatment for $24 \mathrm{hr}$. 


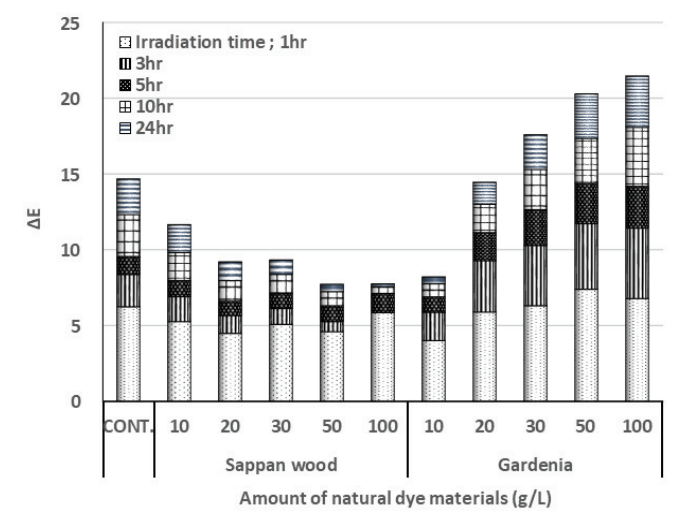

Fig. 2. Changes in colour difference of Re-WDF by ultraviolet irradiation time and amount of natural dye materials.

wood fiber itself was discolored by ultraviolet. The light fastness of Re-WDF prepared by varying the amount of sappan wood and gardenia tends to be opposite. As the amount of sappan wood increased, the color difference of Re-WDF after a UV irradiation for 24 hours decreased, while gardenia increased. This is due to the insufficient dyeing at low sappan wood and its color difference of Re-WDF is affected by discoloration of the fiber itself. Gardenia has a very poor light fastness. Therefore, it is thought that dyeing yield increases as the amount of gardenia increases and the color difference becomes larger and the light fastness tends to decrease.
From the results above, it was possible to produce Re-WDF of YR or Y series by sappan wood and gardenia and the optimum amount of dye materials was $30 \sim$ $50 \mathrm{~g} / \mathrm{L}$.

\subsubsection{Dyeing properties of sappan wood by $\mathrm{pH}$}

Generally, a sappan wood extract, a polychromatic dye, is known to show different colors by $\mathrm{pH}$. Park et al., (2010) reported that a cotton fabric dyed with a sappan wood extract, a* values were significantly reduced and $b^{*}$ values were significantly increased by addition of acetic acid and colored to yellow in acid and red in alkali. However, the color of dyeing by sappan wood extract is not influenced by $\mathrm{pH}$ alone, but is considered to be greatly affected by mordants and the type of water used. After adjusting the $\mathrm{pH}$ of sappan wood extract $(50 \mathrm{~g} / \mathrm{L})$ to $4.5 \sim 12.3$ with $0.1 \mathrm{M} \mathrm{NaOH}$ solution, the resulting color properties of Re-WDF are shown in Table 2.

Both color yield and color difference showed the highest value at $\mathrm{pH} 9.1$. The $\mathrm{a}^{*}$ was 10.31 at $\mathrm{pH} 4.5$ but increased to 13.07 at $\mathrm{pH} 9.0$ and the $\mathrm{b}^{*}$ increased to 34.62 from 30.44 . The results showed that both the red and yellow were strengthened. However, the hues of Re-WDF with sappan wood at $\mathrm{pH} 4.5 \sim 12.3$ were 9.4YR $\sim 8.1$ YR. The hues were slightly reddish yellow rather than red and closer to reddish yellow with an

Table 2. Color changes of the Re-WDF with sappan wood at different $\mathrm{pH}$

\begin{tabular}{cccccccccc}
\hline & \multirow{2}{*}{$\mathrm{KH} / \mathrm{S}$ at } & \multicolumn{4}{c}{ Hunter's Value } & \multicolumn{3}{c}{ Munsell's Value } \\
\cline { 3 - 9 } & $450 \mathrm{~nm}$ & $\mathrm{~L} \mathrm{~L}^{*}$ & $\mathrm{a}^{*}$ & $\mathrm{~b}^{*}$ & $\Delta \mathrm{E}^{*}$ & $\mathrm{H}$ & $\mathrm{V}$ & $\mathrm{C}$ \\
\hline \hline 4.5 & 1.53 & 70.69 & 10.31 & 30.44 & 11.10 & $9.4 \mathrm{YR}$ & 7.01 & 5.10 \\
7.5 & 1.60 & 70.06 & 10.80 & 30.52 & 11.70 & $9.2 \mathrm{YR}$ & 6.94 & 5.16 \\
9.1 & 2.32 & 67.03 & 13.07 & 34.62 & 17.27 & $8.9 \mathrm{YR}$ & 6.65 & 5.94 \\
11.0 & 1.52 & 65.64 & 9.42 & 22.16 & 11.23 & $8.0 \mathrm{YR}$ & 6.47 & 3.96 \\
12.3 & 1.28 & 67.10 & 8.25 & 20.41 & 9.62 & $8.1 \mathrm{YR}$ & 6.61 & 3.58 \\
\hline
\end{tabular}

1) $\mathrm{pHs}$ are adjusted with $0.1 \mathrm{M} \mathrm{NaOH}$ solution

2) Dyeing conditions : Sappan wood : $50 \mathrm{~g} / \mathrm{L}$, Temperature : $60{ }^{\circ} \mathrm{C}$, Time : 60 minutes 
increasing $\mathrm{pH}$. Therefore, the color of dyed woody fiber with sappan wood can be expressed in various colors by other factors such as the type of water used in dyeing, $\mathrm{pH}$, etc. Thus, it is regarded that more careful attention is required to develop a consistent color.

\subsubsection{Dyeing time, dyeing temperature and dyeability}

Dyeing of the fibers is accomplished by diffusing the dye onto the fiber surface, adsorbing it onto the fiber surface, and diffusing it into the fiber. The dyeing time depends on the diffusion speed of dye into the fiber and when the dyeing temperature is increased, the kinetic energy of the dye molecules increases to accelerate the dyeing speed, shortens the dyeing equilibrium time, and affects the amount of dye fixation. When dyeing regenerated wood fiber by sappan wood and gardenia at dye materials of $50 \mathrm{~g} / \mathrm{L}$, the dyeing yield according to dyeing temperature and dyeing time is shown in Fig. 3 and 4, respectively. At 60 minutes of dyeing time, the dyeing yield of Re-WDF dyed by changing the dyeing temperature to $50 \sim 80{ }^{\circ} \mathrm{C}$ showed little difference between $1.77 \sim 1.96$ in sappan wood. The gardenia showed its highest 7.04 at $60{ }^{\circ} \mathrm{C}$ and then decreased again. Hues and color differences of Re-WDF dyed with sappan wood by changing the dyeing temperature also showed no significant difference between $9.0 \sim 9.5 \mathrm{YR}, 12.93 \sim 14.44$, and Gardenia $0.4 \sim 1.2 \mathrm{Y}, 58.02 \sim 59.51$. Therefore, the temperature should be above $50{ }^{\circ} \mathrm{C}$ for the sappan wood and $60{ }^{\circ} \mathrm{C}$ for the gardenia.

By varying the dyeing time to $30 \sim 150$ minutes, the dyeing yields of Re-WDF dyed with sappan wood and gardenia at $60{ }^{\circ} \mathrm{C}$ of dyeing temperature were slightly higher at 60 minutes but there were little difference between $30 \sim 150$ minutes in 2 type natural dyes. Hues and color differences of Re-WDF dyed by changing the dyeing time also showed no significant difference between $9.0 \sim 9.5 \mathrm{YR}, 12.93 \sim 14.44$ in sappan

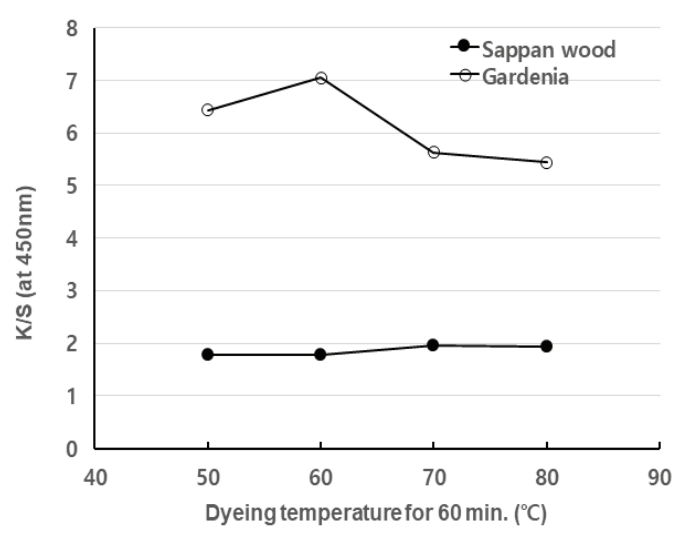

Fig. 3. Color yield of the Re-WDF with natural dyes according to dyeing temperature.

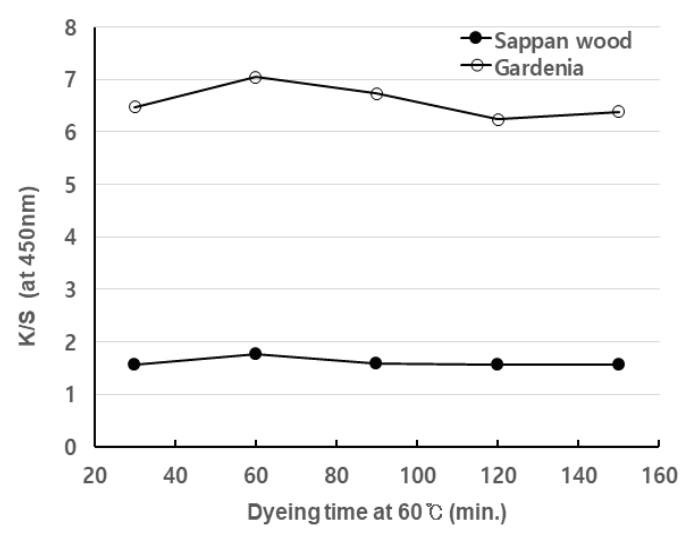

Fig. 4. Color yield of Re-WDF with natural dyes according to dyeing time.

wood, $0.4 \sim 1.2 \mathrm{Y}, 58.02 \sim 59.51$ in gardenia, respectively. Therefore, the dyeing time at $60{ }^{\circ} \mathrm{C}$ should be sufficient for 60 minutes.

Based on the results above, we concluded that dye materials of $50 \mathrm{~g} / \mathrm{L}$, dyeing temperature of $60{ }^{\circ} \mathrm{C}$ and dyeing time of 60 minutes are suitable for the production of Re-WDF by sappan wood and gardenia.

\subsubsection{Premordanting and dyeing properties}

The most important things in dyeing regenerated fibers are the adsorption and bonding between the fibers 
and the dyes. In general, hydrogen bonds or van der Waals forces form bonds between the components of the natural dyes and fibers. However, inducing coordination bonds by adding metals can increase the dyeing yield and improve the light fastness. The mordanting methods of natural dyes include premordanting, postmordanting and simultaneous mordanting as the color and color yield of dyed fibers vary by the these methods. Re-WDFs are prepared according to premordanting with aluminum ammonium sulfate dodecahydrate (Al), Copper (II) acetate anhydrous $(\mathrm{Cu})$, Iron (II) sulfate heptahydrate (Fe), then they get dyed with sappan wood and gardenia extracts solution. The absorbance curves of these for each wavelength are shown in Fig. 5.

The absorbance of the regenerated fiber dyed with sappan wood ( $\mathrm{pH}$ 7.5) was higher in $\mathrm{Al}, \mathrm{Cu}$ and $\mathrm{Fe}$ mordant than in no mordant. The wavelength showing the maximum absorbance shifted to $510 \mathrm{~nm}$ for $\mathrm{Al}$, $520 \mathrm{~nm}$ for $\mathrm{Cu}$, and $530 \mathrm{~nm}$ for Fe. However, in case of gardenia it was thought that there was almost no difference in color according to the mordants because it showed almost no difference in the wavelengths showing the maximum absorbance and absorbance curve patterns regardless of the mordant type.

Fig. 6 shows the dyeing yield of Re-WDF dyed with sappan wood and gardenia after premordanting by $\mathrm{Al}$, $\mathrm{Cu}$ and $\mathrm{Fe}$ mordants at $\lambda$ max. The dyeing yield of nonemordant Re-WDF with sappan wood was 1.53 , but $\mathrm{Al}$ premordant was 5.01, $\mathrm{Cu}$ was 6.47 , and $\mathrm{Fe}$ was 6.35. The dyeing yields were greatly increased by premordanting from the three type mordants. On the other hand, the dyeing yield was the highest in nonemordanting in the case of gardenia and there was no significant difference from the three different mordants.

Table 3 shows the color characteristics of Re-WDF dyed with sappan wood and gardenia after premordanting with $\mathrm{Al}, \mathrm{Cu}$ and $\mathrm{Fe}$ mordants. The color

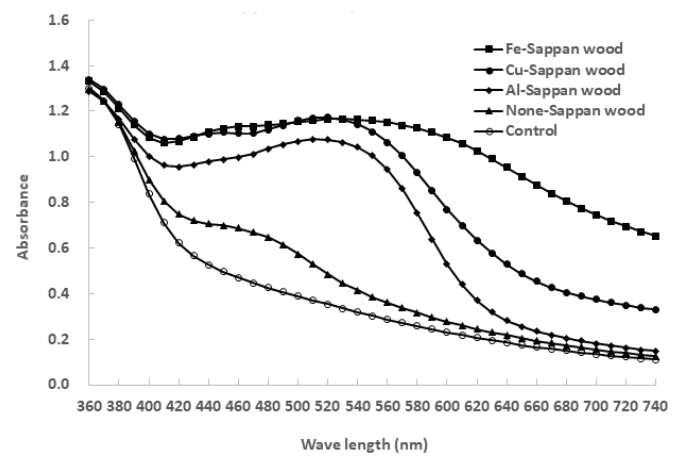

A : Sappan $\operatorname{wood}(\mathrm{pH} 7.5)$

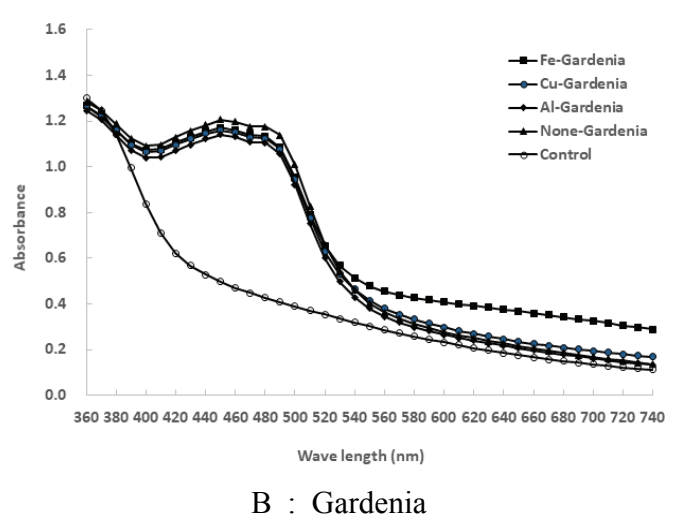

Fig. 5. Absorbance curves of the Re-WDF dyed with sappan wood and gardenia after premordanting by Al, $\mathrm{Cu}$ and $\mathrm{Fe}$ mordants.

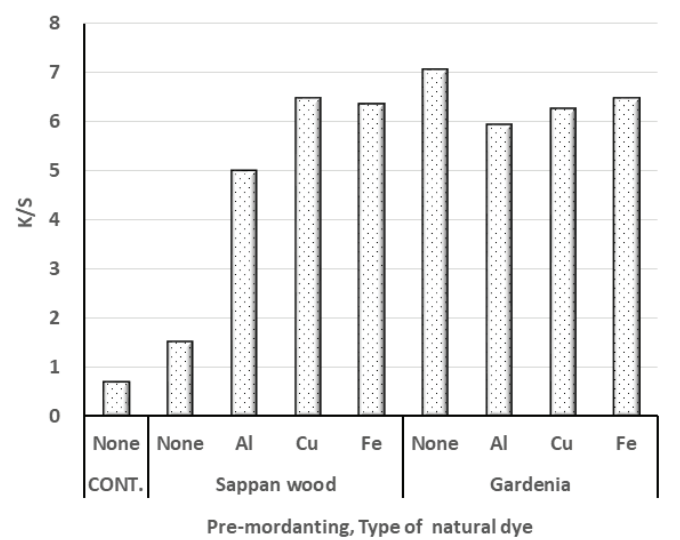

Fig. 6. Color yield of the Re-WDF with sappan wood and gardenia after premordanting by $\mathrm{Al}, \mathrm{Cu}$ and $\mathrm{Fe}$ mordants. 
Table 3. Color changes of the Re-WDF dyed with sappan wood and gardenia after premordanting by $\mathrm{Al}, \mathrm{Cu}$ and $\mathrm{Fe}$ mordants

\begin{tabular}{|c|c|c|c|c|c|c|c|c|c|c|c|}
\hline \multirow{3}{*}{$\begin{array}{l}\text { Type of } \\
\text { natural dye }\end{array}$} & \multirow{3}{*}{$\begin{array}{l}\text { Type of pre- } \\
\text { mordanting }\end{array}$} & \multicolumn{4}{|c|}{ Hunter's Value } & \multicolumn{6}{|c|}{ Munsell's Value } \\
\hline & & \multirow{2}{*}{$\mathrm{L}^{*}$} & \multirow{2}{*}{$a^{*}$} & \multirow{2}{*}{$\mathrm{b}^{*}$} & \multirow{2}{*}{$\Delta \mathrm{E}^{*}$} & \multicolumn{2}{|c|}{$\mathrm{H}$} & \multicolumn{2}{|c|}{$\mathrm{V}$} & \multicolumn{2}{|c|}{$\mathrm{C}$} \\
\hline & & & & & & Before & After ${ }^{2)}$ & Before & After ${ }^{2)}$ & Before & After ${ }^{2)}$ \\
\hline Control & None & 76.05 & 5.21 & 22.18 & & $0.2 \mathrm{Y}$ & $0.6 \mathrm{Y}$ & 7.52 & 6.68 & 3.45 & 5.27 \\
\hline \multirow{4}{*}{$\begin{array}{l}\text { Sappan } \\
\text { wood }^{11}\end{array}$} & None & 70.06 & 10.80 & 30.52 & 11.70 & $9.2 \mathrm{YR}$ & $8.9 \mathrm{YR}$ & 6.94 & 6.17 & 5.16 & 5.75 \\
\hline & $\mathrm{Al}$ & 47.42 & 35.86 & 16.08 & 42.39 & $4.6 \mathrm{R}$ & $9.0 \mathrm{R}$ & 4.66 & 4.81 & 8.61 & 6.19 \\
\hline & $\mathrm{Cu}$ & 39.39 & 24.34 & 9.81 & 43.16 & $4.2 \mathrm{R}$ & $1.9 \mathrm{YR}$ & 3.86 & 3.89 & 5.58 & 4.26 \\
\hline & $\mathrm{Fe}$ & 32.98 & 6.57 & -0.46 & 48.68 & $6.9 \mathrm{RP}$ & $5.7 \mathrm{YR}$ & 3.21 & 3.45 & 1.31 & 1.52 \\
\hline \multirow{4}{*}{ Gardenia } & None & 66.32 & 17.52 & 59.51 & 40.50 & $0.4 \mathrm{Y}$ & $0.6 \mathrm{Y}$ & 6.64 & 6.54 & 9.75 & 6.43 \\
\hline & $\mathrm{Al}$ & 67.88 & 15.53 & 57.99 & 38.15 & $1.0 \mathrm{Y}$ & $0.7 \mathrm{Y}$ & 6.79 & 6.64 & 9.34 & 6.20 \\
\hline & $\mathrm{Cu}$ & 65.83 & 15.31 & 55.90 & 36.66 & $0.8 \mathrm{Y}$ & $0.7 \mathrm{Y}$ & 6.58 & 6.30 & 9.01 & 6.00 \\
\hline & $\mathrm{Fe}$ & 61.03 & 9.25 & 48.36 & 30.45 & $2.8 \mathrm{Y}$ & $2.2 \mathrm{Y}$ & 6.08 & 6.08 & 7.34 & 4.92 \\
\hline
\end{tabular}

1) Sappan wood ; $\mathrm{pH}=7.5$, Dyeing conditions ; Temperature : $60{ }^{\circ} \mathrm{C}$, Time : 60 minutes

2) After of $24 \mathrm{hr}$ ultraviolet irradiation treatment.

difference of Re-WDF dyed with only sappan wood was $11.7, \mathrm{Al}$ premordanting was $42.39, \mathrm{Cu} 43.16, \mathrm{Fe}$ 48.68 and the colors completely changed by premordanting. The hue of Re-WDF dyed with only sappan wood was reddish yellow (9.2YR), Al premordanting was 4.6R, $\mathrm{Cu} 4.2 \mathrm{R}$, but Fe premordanting was colored purplish red (6.9R). The hue of Re-WDF dyed with gardenia, all three types of mordants were $0.8 \sim 2.8 \mathrm{Y}$, which is slightly darker than $0.4 \mathrm{Y}$ of nonemordanting, and there was little difference in color according to mordants. The color of the Re-WDF dyed with nonemordanting sappan wood showed almost no difference between 9.2YR before a 24 hours of UV treatment and 8.9YR after treatment. However, the color of Re-WDF dyed with sappan wood after Al premordanting was varied from $4.0 \mathrm{R}$ to $9.0 \mathrm{R}$ by a $\mathrm{UV}$ treatment for 24 hours, and $\mathrm{Cu}$ premordanting was transformed from red to slightly yellowish red (from $4.2 \mathrm{R}$ to $1.9 \mathrm{YR}$ ), and Fe premordanting from 5.7 YR to 6.9 RP. On the other hand, there was almost no change in color after a 24 hours of UV treatment in the case of gardenia for either none or premordanting with three type of mordants.

Fig. 7 showed the color difference after a 24 hours of UV irradiation treatment for Re-WDF which was dyed with sappan wood and gardenia after premordanting by three mordants of $\mathrm{Al}, \mathrm{Cu}$ and $\mathrm{Fe}$. The color difference of regenerated wood fiber after irradiating the ultraviolet for 24 hours was much greater compar-

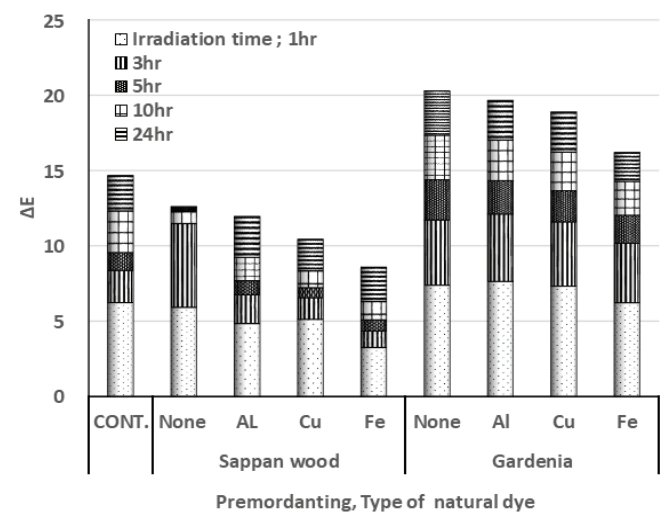

Fig. 7. Changes in color difference of Re-WDF dyed with sappan wood and gardenia after premordanting by ultraviolet irradiation time and type of premordanting. 
ing to the color before the ultraviolet irradiation. This means that the undyed regenerated fiber is also greatly discolored by ultraviolet irradiation. The color difference of undyed regenerated fiber after a UV treatment was greater than that of Re-WDF with sappan wood but was smaller than that of gardenia. From this result, it was confirmed that light fastness was somewhat improved by dyeing with sappan wood, but was deteriorated by dyeing with gardenia. To rank the degree of light fastness regarding types of mordants, the highest was $\mathrm{Fe}$ premordanting regenerated fiber at both sappan wood and gardenia dye followed by $\mathrm{Cu}$ and Al mordant.

\subsection{Commercial Indigo Dyeability}

Indigo is a classic blue-based natural dye obtained by extracting and fermenting from Persicaria tinctoria. Indigo is not soluble in water and is used to make water-soluble leuco compounds by reducing them with a reducing agent such as sodium hydrosulfite under alkali for dyeing. The leuco compound has a strong affinity with cellulose and it is dyed blue when absorbed into cellulose and oxidized with air or an oxidizing agent. In this study, the possibility of producing blue tone Re-WDF was investigated with commercially available indigo powder, sodium hydrosulfite and sodium carbonate anhydrous as reducing agents, and by air oxidation. The color and color difference of Re-WDF dyed with different indigo concentrations of 1,3 and 5 (\%, O.W.F) and the colors before and after a 24 hours of UV treatment are shown in Table 4. The maximum wavelength of indigo-dyed regenerated fibers was $650 \mathrm{~nm}$, and as the concentration of indigo increased from $1 \%$ to $5 \%$, the dyeing yields increased from 0.43 to 6.69 .

In addition, the color difference was 13.03 at indigo concentration of $1 \%$, and it greatly increased as the concentration increased. The color of the Re-WDF with different concentrations of indigo was greenish yellow series $(2.0 \mathrm{GY})$ at $1 \%$, green series $(9.4 \mathrm{G})$ at $3 \%$ and blue series (7.9B) at $5 \%$. Therefore, it is possible to manufacture Re-WDF exhibiting a green and blue-based color by adjusting the concentration of indigo.

Fig. 8 showed the color difference of Re-WDF with different indigo concentrations by ultraviolet irradiation time. As the concentration of indigo increased from $1 \%, 3 \%$ to $5 \%$, the color difference after a $24 \mathrm{hr} \mathrm{UV}$ irradiation decreased to $11.88,7.73$, and 4.25 , and that greatly improved light fastness. Most natural dyes have changed to another color with NBS units of color difference of 12 or more after a 24 hours of ultraviolet irradiation, but indigo is "appreciable" (critical remark of color difference of NBS). The color fastness of indigo was relatively good.

Table 4. Color changes of the dyed regenerated-woody fiber with various concentration of commercial indigo dye

\begin{tabular}{|c|c|c|c|c|c|c|c|c|c|c|c|c|}
\hline \multirow{3}{*}{$\begin{array}{l}\text { Concentration } \\
\text { of Indigo } \\
(\%, \text { O.W.F. })\end{array}$} & \multirow{3}{*}{$\begin{array}{c}\lambda \max \\
(\mathrm{nm})\end{array}$} & \multirow{3}{*}{$\mathrm{K} / \mathrm{S}$} & \multicolumn{4}{|c|}{ Hunter's Value } & \multicolumn{6}{|c|}{ Munsell's Value } \\
\hline & & & \multirow{2}{*}{$\mathrm{L}^{*}$} & \multirow[b]{2}{*}{$a^{*}$} & \multirow{2}{*}{$\mathrm{b}^{*}$} & \multirow{2}{*}{$\Delta \mathrm{E}^{*}$} & \multicolumn{2}{|c|}{$\mathrm{H}$} & \multicolumn{2}{|c|}{$\mathrm{V}$} & \multicolumn{2}{|c|}{$\mathrm{C}$} \\
\hline & & & & & & & Before & After ${ }^{2)}$ & Before & After $^{2)}$ & Before & After $^{2)}$ \\
\hline 0 & 450 & 0.73 & 76.05 & 5.21 & 22.18 & & $0.2 \mathrm{Y}$ & $0.6 \mathrm{Y}$ & 7.52 & 6.68 & 3.45 & 5.27 \\
\hline 1 & 650 & 0.43 & 69.49 & -4.72 & 16.89 & 13.03 & $2.0 \mathrm{GY}$ & $3.9 \mathrm{Y}$ & 6.84 & 6.13 & 2.30 & 3.40 \\
\hline 3 & 650 & 2.40 & 53.09 & -8.66 & 2.09 & 33.52 & $9.4 \mathrm{G}$ & $7.8 \mathrm{GY}$ & 5.15 & 4.75 & 1.70 & 1.69 \\
\hline 5 & 650 & 6.69 & 38.96 & -6.84 & -8.67 & 49.73 & $7.9 \mathrm{~B}$ & $3.9 \mathrm{~B}$ & 3.75 & 3.60 & 2.49 & 1.78 \\
\hline
\end{tabular}

1) Dyeing conditions ; Temperature : $60{ }^{\circ} \mathrm{C}$, Time : 60 minutes

2) After of $24 \mathrm{hr}$ ultraviolet irradiation treatment. 


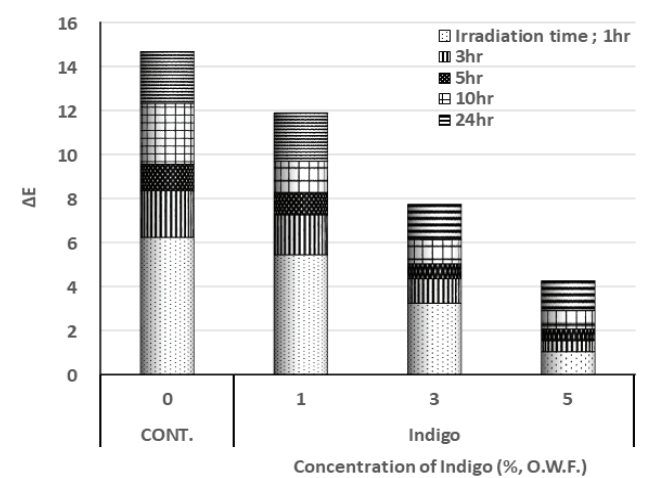

Fig. 8. Changes in color difference of Re-WDF by ultraviolet irradiation time and concentration of commercial indigo dye.
Based on the results above, the colors that can be developed by natural dyes such as sappan wood, gardenia and indigo on Re-WF from wMDF are shown in Table 5. It was possible to prepare Re-WDF with sappan wood showing R- and YR-based color by Al, $\mathrm{Cu}$ premordanting and RP-based color by $\mathrm{Fe}$ premordanting. In the case of gardenia, only Y-based color was developed by none, $\mathrm{Al}$. $\mathrm{Cu}$ and $\mathrm{Fe}$ premondanting. Indigo was able to produce Re-WDF that exhibited GY tone color at $1 \%$ concentration, $\mathrm{G}$ tone at $3 \%$, and $\mathrm{B}$ tone at $5 \%$ or more.

Table 5. Color of dyed regenerated-woody fiber sheets in this study

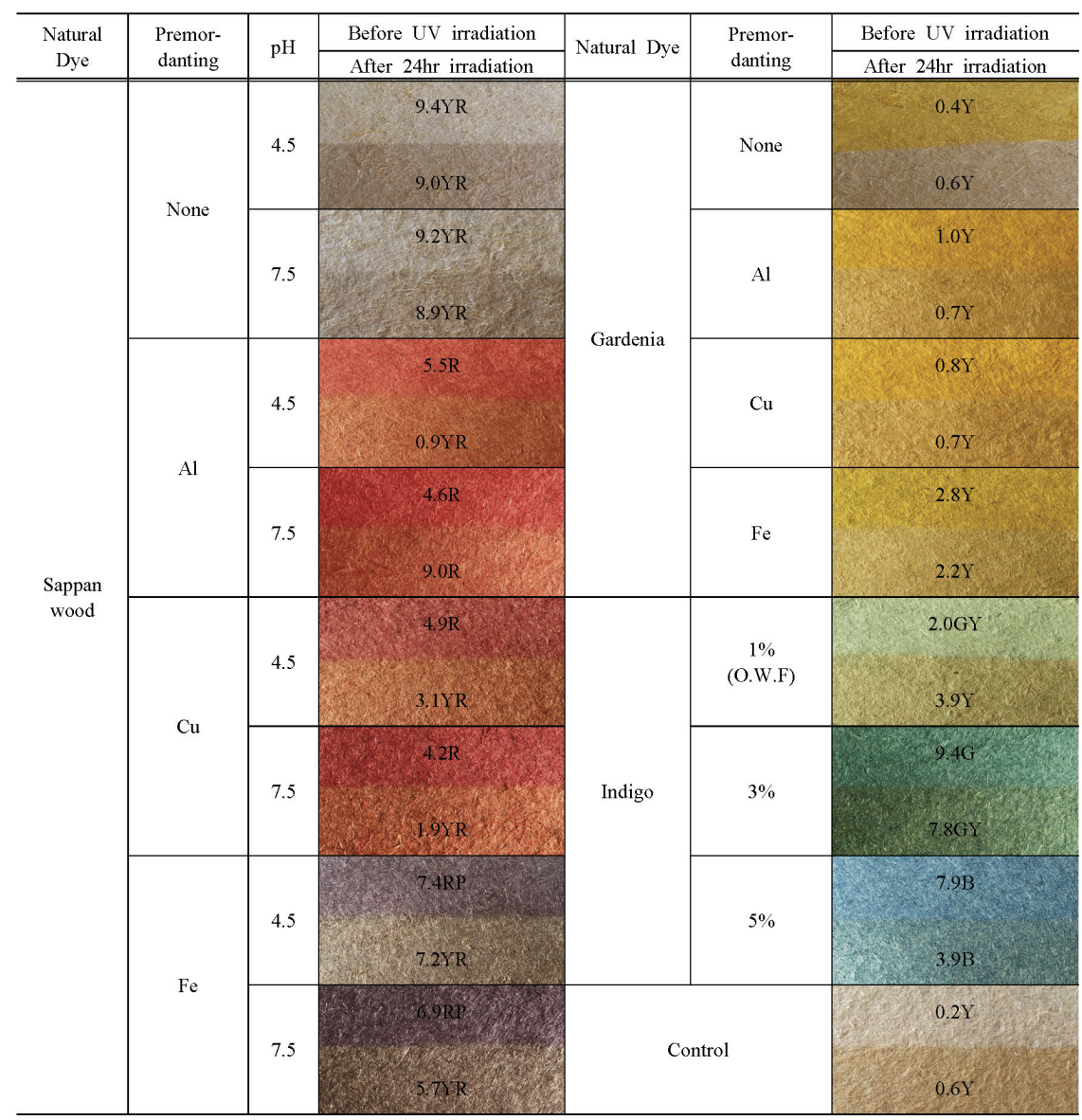




\section{CONCLUSION}

The results of the dyeing characteristics of regenerated fiber from wMDF made of pitch pine and using natural dyes such as sappan wood which is polychromatic natural dyes as red series, monochromatic gardenia as yellow series and indigo as blue series were as follows.

Indigo was able to produce Re-WDF that exhibited GY tone at $1 \%$ concentration, $\mathrm{G}$ tone at $3 \%$, and $\mathrm{B}$ tone at $5 \%$ or more. Indigo had the best light fastness, followed by sappan wood and gardenia. However, in the case of sappan wood, the light fastness was somewhat improved by premordanting, but gardenia's was poor by premordanting

The dyeing yield and color difference of Re-WDF dyed with sappan wood and gardenia increased as the amount of dye materials increased from $10 \mathrm{~g} / \mathrm{L}$ to 100 $\mathrm{g} / \mathrm{L}$. The optimum dyeing temperature and dyeing time were examined at $50 \mathrm{~g} / \mathrm{L}$ of dye materials for 60 minutes at $60{ }^{\circ} \mathrm{C}$. Under these conditions, Re-WDF dyed with sappan wood developed YR series color, and gardenia Y series color. The colors of Re-WDF with sappan wood extract solution (distilled water) adjusting to $\mathrm{pH}$ $4.5 \sim 12.3$ were $9.4 \mathrm{YR} \sim 8.1 \mathrm{YR}$, which were yellow with a little bit of red. The hue of RE-WDF dyed with only sappan wood was reddish yellow (9.2YR), $\mathrm{Al}$ and $\mathrm{Cu}$ premordanting were $\mathrm{Red}(\mathrm{Al} 4.6 \mathrm{R}, \mathrm{Cu} 4.2 \mathrm{R})$, but Fe premordanting was purplish red (6.9R). In the case of gardenia, only Y-based color was developed by none, $\mathrm{Al}, \mathrm{Cu}$ and $\mathrm{Fe}$ premondanting.

It is possible to manufacture blue, red, and yellow Re-WDF by natural dyes, but more research is needed to improve the light fastness and discuss the relationship between the dye, water, mordanting method, and $\mathrm{pH}$, etc.

\section{ACKNOWLEDGMENT}

This study was supported by the Gyeongnam National University of Science and Technology Grant in 2018.

\section{REFERENCES}

Choi, T.H., Yoo, S.I., Lee, S.H., Jeong, H.W., Yang, E.J. 2009. Natural dyeing of Hanji with Alnus japonica fruit extractive. Journal of the Korean Wood Science and Technology 37(4): 414-420.

Jeon, C., Jin, Y.M. 2000. Studies on the dyeing of Hanji by natural dye-stuffs (I): With a focus on the color tone yellow color series. Journal of Korea TAPPI 32(3): 48-56.

Jeon, C. 2003. Studies on the dyeing of Hanji by natural dye-stuffs (II): With a focus on the onion-peelings. Journal of Korea TAPPI 35(1): 48-53.

Jeon, C., Ahn, Y.H., Jeon, H.J. 2006. Studies on the dyeing of Hanji by natural dye-stuffs (III): With a focus on the mugwort. Journal of Korea TAPPI 38(3): 61-65.

Jeon, C., Ahn, Y.H., Jeon, H.J. 2006. Studies on the dyeing of Hanji by natural dye-stuffs (IV): With a focus on the clove tree. Journal of Korea TAPPI 38(3): 66-71.

Jo, H.J., Lee, S.K., Lee, H.J., Kang, H.Y., Choi, D.H., Choi, I.G. 2007. The dyeing properties of Hanji by Neolitsea sericea Koidz extracts. Journal of Korea TAPPI 39(2): 60-67.

Ju, S.G., Roh, J.K. 2017. Manufacture of dyed recycling woody fiber using waste MDF Journal of the Korean Wood Science and Technology 45(3): 297-307.

Ju, S.G., Roh, J.K. 2019. The dyeing properties of woody fiber regenerated from waste MDF by reactive dyes. Journal of the Korean Wood Science and Technology 47(2): 163-177.

Lee, S.H., Yoo, S.I., Choi, M.G., Sin., S. Choi, T.H.. 2009. Natural dyeing characteristics of black color to the Korean traditional hand-made paper(Hanji). Journal of the Korean Wood Science and Technology 37(4): 406-413.

Lee, S.R., Kim, I.H., Nam, S.W. 2002. A study on the component analysis of sappan wood extracts. 
Journal of the Korean Society of Dyers and Finishers 14(4): 33-43.

Park, M.O., Yoon, S.L. 2009. Properties of natural dyeing of bast fiber(Part 1). Properties of dye and extraction condition of sappan wood, gardenia and gallnut. Journal of Korea TAPPI 41(3): 49-56.

Park, M.O., Yoon, S.L. 2010. Properties of natural dyeing of bast fiber(Part 2). Pre mordanting dyeing of sappan wood, gardenia and gallnut. Journal of Korea TAPPI 42(2): 1-14.

Park, M.O., Yoon, S.L. 2011. Properties of natural dyeing of bast fiber(Part 3). Combination dyeing of gallnut-sappan wood and gardenia. Journal of Korea TAPPI 43(1): 1-10.

Park, S.Z., Kang, J.Y., Seol, D.W., Yang, H.M., Lee, J.M., Choi, H.J., Han, S.Y., Jeon, D.W. 2010. Effect of the change of $\mathrm{pH}$ condition on the dyeing using Caesalpinia sappan. Journal of Fashion Business 14(2): 138-150.
Tak, E.S., Bae, M.W., Kang, S.H., Bae, Y.J., Kang, S.Y., Jung, S.K., Hong, I.K. 2010. Presentation of target color with extraction variables in natural dyes extraction. Applied Chemistry for Engineering 21(5): 559-563.

Watanabe, T., Yamamoto, A., Naga, S., Terabe, S. 1998. Separation and constituents in Determination of yellow gardenia pigments for food and iridoid constituents in gardenia fruits by micellar electrokinetic chromatography. Food Science and Technology International Tokyo 4(1): 54-58.

Yoo, S.I., Oh, S.K., Lee, S.H., Choi, T.H. 2009. Dyeing of Hanji with flowers of pagoda tree (Sophora japonica). Journal of Korea TAPPI 41(2): 34-39.

Yoo, S.I., Oh, U.M., Min, Y.R., Choi, T.H. 2011. Improvement on dyeability of Hanji with natural dyes using a (3-chloro-2-hydroxypropyl) trimethyl ammonium chloride. Journal of Korea TAPPI 43(3): 34-39. 